\title{
Employment Status, Quality of Matching, and Retirement in Korea: Evidence from Korean Longitudinal Study of Aging ${ }^{1}$
}

\author{
Chulhee Lee and \\ Department of Economics, Seoul National University, 599 Kwanak-ro, Kwanak-gu, Seoul, South \\ Korea, Phone: +82-2-880-6397, Fax: +82-2-886-4231 \\ Jinkook Lee \\ Labor \& Population, Rand Corporation, 1776 Main St., P.O. Box 2138, Santa Monica, CA \\ 90407-2138, USA \\ Chulhee Lee: chullee@snu.ac.kr; Jinkook Lee: Jinkook@rand.org
}

\begin{abstract}
This paper explores the differing probabilities of retirement for self-employed and wage-andsalary workers. It finds self-employed workers are less likely to retire than wage-and-salary ones, and that differences in retirement incomes, health, productivity, job characteristics, and compulsory retirement practices do not explain the disparity. The difference between selfemployed and wage-and-salary workers in the quality of matching between the job and the worker (i.e., between required and desired amount of work) explains the later retirement of the selfemployed. We note the implications of these findings for labor-force participation at older ages and how policies might boost employment of the elderly.
\end{abstract}

\section{Keywords}

Retirement; Self-employment; Employment; Ageing; Job Flexibility

\section{Introduction}

One of the most notable labor-market changes in developed countries over the last several decades has been the sharp decrease in the labor-force participation rate of older males. This has become a major social issue as the relative size of the aged population has grown in many countries. Decreasing labor-force participation by older workers could aggravate problems, such as labor shortages and financial pressure on pension funds, associated with population ageing. ${ }^{2}$ One possible policy response to these problems would be boosting employment of older workers. Better understanding the labor-market behavior of older individuals can help guide effective policy solutions. Accordingly, many economists have undertaken recent research on retirement decisions and the causes of decreasing labor-force participation of older men. ${ }^{3}$

As one of the most rapidly ageing countries in the world today, South Korea (hereafter Korea) faces many of these same issues associated with older workers. However, its older workers are distinct from those in other OECD nations in that its labor-force participation

\footnotetext{
${ }^{1}$ We thank Jim Smith and Randall Olsen for their helpful comments and suggestions. This research is supported by the National Institute of Aging, the National Institutes of Health (R21 AG027288).

${ }^{2}$ According to Lee (2001), the expected length of male retirement in the United States has increased by sevenfold since 1850, representing as much as 30 percent of the remaining life of the current labor-market cohort.
} 
rate for older men increased substantially from the mid-1960s to 1997 (Lee, 2007). Although it fell dramatically after the Asian financial crisis of 1997, the current level of labor-force participation of older Korean men remains above that in other OECD countries.

In this paper, we explore the retirement behavior of older self-employed workers in Korea, particularly the differing probabilities of retirement for the self-employed and wage earners. We investigate how the quality of matching between the job and the worker (i.e., between required and desired amount of work) differs for the self-employed and wage workers and whether such differences matter in retirement decisions.

Addressing these issues is important to understanding the current patterns and anticipating future changes in labor-market activity of elderly Koreans. While influences (e.g., socialinsurance programs and personal health) on individual decisions to supply labor are relatively well understood, those (e.g., job rigidities) affecting the demand for labor by older workers are less understood (Hurd 1996). Because self-employment and wage-and-salary jobs differ greatly different in their requirements and flexibility, comparing retirement behaviors by employment status can provide useful insights pertaining to how demand-side factors affects the timing of their departure from the labor market.

Studying the patterns of work and retirement of the self-employed is a key to understanding some peculiar features of older workers in Korea. The self-employed, particularly males, account for a much larger fraction of the labor force in Korea than in other nations with comparable economic development. ${ }^{4}$ Most male Korean workers 45 or older are selfemployed. ${ }^{5}$ A considerable number of wage-and-salary workers switch to self-employment after leaving or losing their lifetime jobs.

The high proportions of self-employed, as well as relatively immature social-insurance programs, are among the explanations for higher economic activity among older Koreans. In particular, the increase in labor-force participation among older Korean men prior to 1997 is largely attributable to the increase among older men in rural areas, where a much higher proportion of older workers are self-employed (Lee, 2007).

Given the high proportion of older Koreans who are self-employed, job creation in the selfemployment sector is regarded as a means to boost the employment of older persons in Korea. To evaluate whether policies to accomplish this would be appropriate, we must understand why self-employed workers retire later than wage-and-salary workers in Korea. If they can stay in the work force longer because self-employment is a more favorable type of work for older persons, then encouraging self-employment of older workers could be a sensible policy. If older self-employed workers in Korea are simply being forced to work

\footnotetext{
${ }^{3} \mathrm{~A}$ large number of studies have focused on the impact of the implementation and expansion of public pension programs on the labor force participation of older men (Boskin, 1977; Parsons, 1980, 1991; Hurd and Boskin, 1984; Krueger and Pischke, 1992; Lee, 1998; Gruber and Wise, 1999, 2004; Friedberg and Webb, 2005). Still others have noted how health, asset price, and other social programs affect retirement decisions (McGarry, 2004; Gruber and Madrian, 1995; Coile and Levine, 2006). A growing number of studies have examined how employment conditions, changing industrial structure, and technology have influenced retirement decisions (Bartel and Sicherman, 1993; Hurd and McGarry, 1993; Hurd, 1996; Friedberg, 2003; Aubert et al., 2006).

${ }^{4}$ Studies on self-employed workers have been growing in Korea, even as the proportion of the workers who are self-employed has shrunk in recent years (Keum and Cho, 2000; Cheon, 2003; Ryoo, 2005). Among explanations for growth in the proportion of selfemployed prior to the financial crisis of the late 1990s are (1) increased unemployment and reduced job security for middle-aged wage and salary workers (Sung and Ahn, 2004; Cheon, 2003) and (2) a long-term rise in the attractiveness of self-employment (Ryoo and Choi, 2000; Ryoo, 2005).

${ }^{5}$ Even in the non-farm sector, self-employed workers account for 41 percent of male non-farm workers aged 45 and older; among such workers aged 65 and older, 49 percent are self-employed. Although not as important as it is for males, self-employment also accounts for a considerable fraction of the female workforce, including 28 percent of female non-farm workers at least 45 years of age. (Statistics on the size of self-employment in Korea based on authors' calculations using microsample data from the 2005 census.)
} 
longer because of poverty, then encouraging self-employment may not be a good policy option.

We study the retirement behaviors of older Koreans, using data from the 2006 and 2008 waves of the Korean Longitudinal Study of Ageing (KLoSA). Much previous work on Korean retirement behavior has used other panel data sets, especially the Korea Labor and Income Panel Study (KLIPS) (Park, 2001, 2003; Kim and Yoo, 2004; Sung and Ahn, 2006; Choi, 2006). We use the KLoSA for our analysis because of its large sample size of older respondents. This enables us to analyze retirement decisions for individuals of different personal characteristics or employment status, and thereby to consider more completely potential heterogeneity in retirement behaviors.

Although some previous studies have addressed diversity in the retirement process (Park 2001, 2003), their small sample sizes restricted their findings and implications. A recent study by Lee (2008), using the first-wave data of the KLoSA, examines how retirement expectations differ between the self-employed and wage workers, but its reliance on crosssectional data means it has indirect measures of retirement decisions (subjective scores on the probability of continuing to work for a certain number of years) and endogeneity problems. This study is perhaps the first to analyze actual retirement behaviors of such narrowly-defined populations as the self-employed and wage-and-salary workers in Korea.

\section{Related Literature}

Previous literature suggests several reasons why the self-employed may show different retirement behaviors from wage-and-salary workers. Self-employed workers may remain in the labor market longer than wage-and-salary workers because of the more flexible nature of their work. Hurd (1996) notes that labor market rigidities caused by team production, fixed costs of employment, and social security may force many older wage workers to choose between full-time work and complete retirement. Because of the difficulties in adjusting the hours of work and wages to changing tastes and productivity as one ages, wage earners retire earlier than they would if gradual retirement were an option. In the United States, for example, most prime-age male wage-and-salary workers indicated that they could not reduce work hours if they wanted to in their current job (Gustman and Steinmeier, 1985). Some wage-and-salary workers partially retire at old age, but only by transferring to a different job, not being free to do so in their main job (Gustman and Steinmeier, 1984). This suggests that the constraints requiring a minimum number of hours worked on the main job is perhaps a more important reason for partial retirement than the pressure towards retirement in the workplace.

Self-employed workers, because they are more able to undertake partial retirement from their present jobs, may enter full retirement later than wage workers. Quinn, Burkhauser, and Myers (1990) found most older workers who are self-employed either reduced their work hours on their career job or became part-time workers while most wage-and-salary workers left the workforce. In the early-20 ${ }^{\text {th }}$-century United States, self-employed farmers were much less likely to retire than non-farm wage earners (Lee, 2002). Gradual retirement was possible for self-employed farmers because they were able to reduce the hours and intensity of their work by adjusting acreage and crop-mix or by adopting mechanization (Pedersen, 1950).

Within Korea, research on older workers, which has been increasing with rising concern over population ageing, points to more specific reasons for retirement before and after the financial crisis of the late 1990s. Chang (2002), using the 2000-2001 KLIPS, found better health and educational attainment reduced odds of retirement while real-estate wealth 
increased them. She also found the average retirement age of Korean males increased by two years from 1987 to 1997 but decreased after the financial crisis in 1998.

Cho and Kim (2005), using the data from the Workplace Panel Survey, find that Korean corporations, especially after the financial crisis in 1998, use mandatory retirement to deal with exorbitant wage increases that outpace productivity and were in part generated by the traditional seniority-based wage system. They also found mandatory retirement for many firms - with, they suggest, the tacit approval of labor unions-alleviates backlogs in promotion by circumventing the rigidity of the personnel dismissal system under Korean labor law.

Sung and Ahn (2006), using the KLIPS, find that age and years of schooling are negatively related to employment of individuals 45 or older. They also find healthier persons are more likely to be employed while those in areas with high unemployment are less likely. They also found non-wage workers 45 or older that were more likely to remain in labor force than wage-and-salary workers of that age, suggesting that job characteristics matter.

Analyzing a sample of two-earner households drawn from the KLIPS, Choi (2006) finds that pension wealth, other retirement incentives, and spouse's health and wage affect the retirement decisions of Korean men, but that spouse characteristics do not affect the retirement decisions of Korean women. Estimating the cross-wage elasticity of retirement for couples, Choi suggests that spouses' leisure times are complementary, and that effect is much stronger for men than women. For men, the substitution effect of the wages of their spouses dominates the income effect, whereas substitution and income effects cancel out for women.

Lee (2008), using the 2006 KLoSA, explores differences in retirement expectations between the self-employed and wage-and-salary workers. He, too, finds the self-employed expect to remain in the labor market longer than wage-and-salary workers. He also finds differences in retirement income, health, productivity, job characteristics, and compulsory retirement practices cannot explain this result. This suggests that the difference between the self-employed and wage-and-salary workers in the quality of match between job and worker, particularly in required and desired amount of work, may instead explain the later retirement of the self-employed.

\section{Conceptual Framework and Methods}

To construct an empirical model of retirement that is consistent with the actual circumstances of the Korean labour market, we need first to understand who makes the retirement decision. The presence of contractual mandatory retirement in many firms gives an impression that the age of retirement is predetermined for wage-and-salary workers in Korea. Nevertheless, there are several reasons it may be more realistic to assume that retirement is determined by both workers and employers.

Most Korean wage and salary workers (four out of five workers in KLoSA) are employed in firms without a mandatory retirement policy. Furthermore, even in firms with such a policy, a large fraction of employees are forced to retire before the compulsory retirement age. Methods for inducing early retirement include transferring the worker to an unacceptable position or offering pecuniary incentives.

As a result, only a small fraction of wage-and-salary workers leave their jobs because of mandatory retirement. Our calculations from KLoSA data indicate 10 percent of wage-andsalary workers 45 or older who retired between 2006 and 2008 did so because of mandatory retirement policy. 6 
To assess the retirement decision of workers not subject to mandatory retirement, we model the probability of retirement at a point of time as a function of expected net gains from retirement, denoted by $R^{*}$.

$$
R_{i}^{*}=R\left(\bar{Z}-Z_{i}, N_{i}, X_{i}, B_{i}, \theta_{i}\right)
$$

We hypothesize that the costs and benefits of retirement are determined by the discrepancy between the amounts of minimum work effort (such as hours and intensity of work) required by a worker's job (denoted by $\bar{Z}$ ) and the desirable amount of work efforts that individual worker $i$ would choose under no restriction (denoted by $Z_{i}$ ). ${ }^{7} \bar{Z}$ is determined by various jobspecific factors, such as production technology, managerial practices, and labor-market conditions, affecting the demand for labor. $Z_{i}$ is determined by the tastes and productivity of the individual worker $i$. The value of retirement is also determined by the demographic $\left(X_{i}\right)$ and job characteristics $\left(B_{i}\right)$ of the worker not fully captured by the term $\left(\bar{Z}-Z_{i}\right)$ as well as by retirement incomes (denoted by vector $N_{i}$ ). $\theta_{i}$ denotes unobservable personal characteristics.

Ageing diminishes a worker's physical strength and functional ability and reduces the taste for work, decreasing the desirable amount of work effort $\left(Z_{i}\right)$. As long as the minimum work effort required by the job $(\bar{Z})$ remains fixed, the discrepancy $\left(\bar{Z}-Z_{i}\right)$ increases, raising the value of retirement. Thus, the size of $\left(\bar{Z}-Z_{i}\right)$ depends on (1) the quality of matching between the worker and the job in desirable and required amount of work effort and (2) the ability of the worker to change the required work effort $(\bar{Z})$ either within the same job or by switching jobs.

We model an employer's demand for a worker, including the employer's decision to force a worker to retire, as a function of the worker's net contribution to the firm, denoted by $\mathrm{C}^{*}$.

$$
C_{i}^{*}=C\left(X_{i}, B_{i}\right)
$$

This value is largely determined by the worker's wage and productivity (represented by $X_{i}$ ), and by the quality of job characteristics (represented by $B_{i}$, ) that affect the costs of employment.

Considering the circumstance in which retirement decisions are made by both workers and employers, we assume that a worker retires if the expected gain of the worker from retirement $\left(R^{*}\right)$ is positive or the value of net contribution of the worker to the firm $\left(C^{*}\right)$ is negative. This leads to the following reduced-form model of the probability of retirement $\left(P^{R}\right)$ :

$$
P_{i}^{R}=\alpha\left(\bar{Z}-Z_{i}\right)+\beta N_{i}+\gamma X_{i}+\phi B_{i}+\theta_{i}+\varepsilon_{i}
$$

In this model, the difference in the probability of retirement between the self-employed and wage-and-salary workers is attributed to the differences by employment type in (1) retirement incomes $\left(N_{i}\right),(2)$ demographic and job characteristics $\left(X_{i}\right.$ and $\left.B_{i}\right)$ representing,

\footnotetext{
${ }^{6}$ In fact, our analysis of KLoSA data indicates most Korean wage and salary workers make retirement decisions for themselves. We find nearly two-thirds of wage workers who retired between 2006 and 2008 did so for personal reasons. The most commonly cited reasons for retirement included poor health (24.4\%), taking a break (6.0\%), and low wage (5.8\%).

${ }^{7}$ We draw this idea largely from the conceptual framework of Lee (2008). Our study differs from his in analyzing the probability of actual retirement between 2006 and 2008 rather than subjective expectations of continuing to work.
} 
respectively, tastes for work and institutional pressure toward involuntary retirement, (3) unobservable characteristics $\left(\theta_{i}\right)$ that capture self-selections in occupational choice, and (4) the quality of match between the worker and the $\operatorname{job}\left(\bar{Z}-Z_{i}\right)$. The quality of match between worker and job would attribute the more flexible nature of self-employment as the reason self-employed workers remain longer in the labor market.

Using this simple model, we offer the following hypotheses to explain differences in probability of retirement between the self-employed (SE) and wage-and-salary (WS) workers.

1. The SE are poorer than WS workers and therefore have to work longer to accumulate enough money for retirement (referred to as H1).

2. The SE are healthier and more productive than WS workers, and therefore can work to an older age (H2).

3. Job characteristics (i.e. job satisfaction and work requirement) are more favorable for the SE than for WS workers (H3).

4. The SE can work longer than WS workers because of the absence of a mandatory or conventionally determined age of retirement $(\mathbf{H 4})$.

5. Because working conditions and the required minimum amount of work effort are more heterogeneous for the self-employed, it is relatively easy for the SE (especially those who have an unusual preference or capacity) to find a job well matched to them (H5).

6. Given greater job flexibility, the SE can adjust their work efforts to changes in their taste and productivity (H6).

7. If it is difficult to change work effort within an occupation or industry, then the SE can more easily switch to a less demanding job than WS workers (H7).

8. Individuals who retire later selectively enter self-employment (H8).

Of course, these explanations are neither exhaustive nor necessarily mutually exclusive.

Below we examine the difference in the probability of retirement for self-employed and wage-and-salary workers, and determine which of the eight above hypotheses best explains the observed disparity. To do so, we analyze all individuals in KLoSA at least 50 years old who were a wage-and-salary or self-employed worker in 2006. Because part-time employment at old age may indicate gradual retirement, we largely focus on employees working 30 hours or more per week. KLoSA respondents working less than 30 hours weekly in 2006 were nearly twice as likely to retire by 2008 as full-time workers were. We classify as retired a person who in 2008 did not work and answered "retirement" as their reason for not working.

\section{Differences in the Probability of Retirement between the Self-Employed and Wage-and-Salary Workers}

We first compare the probability of retirement for self-employed and wage-and-salary workers. Table 1 shows the percentage of workers in 2006 who had retired by 2008 by sex, age, and employment status. The results generally confirm the widely held belief that the self-employed remain in the labor market longer than wage-and-salary workers. Among self-employed workers at least 50 years old, 7.2 percent had retired by 2008; among wageand-salary workers, 11.4 percent had retired. The difference was particularly sharp for male workers at least 65 years of age; among these, 9.4 percent of the self-employed, and 26.3 
percent of wage-and-salary workers, had retired by 2008. Although this is not a surprising result, it provides the first detailed evidence on the magnitudes and patterns of the differences in the probability of retirement between the self-employed and wage-and-salary workers.

Table 2 shows the percentage of workers who retired between 2006 and 2008 by employment characteristics that may affect retirement decisions. Among older part-time workers (i.e., those who worked fewer than 30 hours per week) in 2006, 14.4 percent had retired by 2008; among older full-time workers, only 8.4 percent had retired. Among all workers, part-time workers at least 65 years of age (26.4 percent) were most likely to retire. Even among those 50 to 54 years of age, part-time workers ( 9.1 percent) were more likely to retire than full-time ones ( 3.2 percent). These results support the conjecture that part-time jobs may bridge full-time employment and complete retirement. Among the self-employed, agricultural workers (4.8 percent) were less likely to retire than nonagricultural workers $(8.2$ percent).

Among self-employed females and individuals aged 60 and older, agricultural workers were only one-half to one-third as likely to retire as non-agricultural ones. The lower retirement rates of self-employed agricultural workers may be due to greater job flexibility in farming.

One key indicator of the economic status and employment conditions of is the self-employed is whether they hire non-family members to help run a business. The self-employed who employ other workers are likely more affluent and may be more able to substitute hired hands for their own efforts. Yet we find little difference in retirement among self-employed who hired employees (7.9 percent) and those who did not (7.1 percent). Among groups of self-employed workers hiring others, males and those less than 65 years of age were less likely to retire.

One of the most popular explanations for why self-employment can lead to later retirement is compulsory retirement policies, most commonly at age 55, for Korean firms, especially large corporations. Indeed, for wage-and-salary workers 55 to 64 years old, mandatory retirement policy appears to have led to retirement rates about twice those for other workers in the same age group who are not subject to such retirement policy. Although this appears to support the popular view, we should remember that wage-and-salary workers with mandatory retirement policy are heavily concentrated in large-scale corporations and public sectors. Thus, it will require regression analyses (provided below) to determine whether institutional policies contribute significantly to differences in retirement rates for the selfemployed and wage-and-salary workers.

Among types of wage-and-salary workers, retirement was more common among the temporarily employed than the regularly employed or the daily employed. It is likely that many older workers among the temporarily employed were, in fact, partially retired.

Table 4 shows how much of the disparity in the probability of retirement between selfemployed and wage-and-salary workers can be explained by differences in (1), retirement incomes ( $N_{i}$ in Equation 1) and (2) demographic and job characteristics $\left(X_{i}\right.$ and $B_{i}$ in Equation 1), representing labor productivity and tastes for work. Table 3 presents the list of variables we included in analysis and their definitions. ${ }^{8}$ Age, years of schooling, hourly

\footnotetext{
${ }^{8}$ These variables include many used in several previous studies (Parsons, 1980; Hurd and Boskin, 1984; Krueger and Pischke, 1992; Costa, 1998; McGarry, 2004) on the timing of retirement. We considered including a variable on the number of children less than 19 years of age, but found several subsamples used for the regressions had no households with children in that age group. Furthermore, the effects we did find for that variable were statistically insignificant for all specifications and subsamples in our analyses, and resulted in little change in the results for other explanatory variables. We therefore report results of regressions excluding this variable.
} 
wage, and health are proxy variables for the individual's productivity in the labor market, which in turn determines the opportunity cost of retirement. Net wealth, expected present values of public and private pensions, and total non-labour income are measures of future retirement incomes. Health, family structure, and hours of work may influence the preference for work. We include variables on marital status, labour-force participation of spouse and the number of children with particular characteristics to capture the potential effect of dependents or family support. A larger family, for example, will require a greater household income but also have a greater potential for earnings from more family members.

We conducted logistic regressions to determine the odds of retirement. ${ }^{9}$ Our focus was whether the greater likelihood of retirement for wage-and-salary workers persisted regardless of retirement-income level and demographic and job characteristics. We first presented the results of logistic regressions for data on the full sample of active workers (Col. 1 of Table 4) and then a subsample excluding wage-and-salary workers subject to compulsory retirement (Col. 2 of Table 4). We then compared the retirement behaviors of the self-employed and wage-and-salary workers after eliminating the impact of mandatory retirement that affect only wage-and-salary workers.

The result for the full sample (Col. 1 of Table 4) suggests that the self-employed are, when controlling for the other variables listed in Table 3, 68 percent (or 7.7 percentage points) less likely to retire than wage-and-salary workers are. ${ }^{10}$ That is, holding constant the individual characteristics pertaining to the first three hypotheses (H1 to H3) on retirement savings, worker health, and job characteristics does not reduce the difference in the probability of retirement by employment status. ${ }^{11}$ Excluding from the analysis wage-and-salary workers subject to mandatory retirement, it appears the self-employed are 70 percent less likely to retire. This suggests mandatory retirement policy does not explain the higher probability of retirement for wage-and-salary workers.

The personal characteristics most associated with a higher probability of retirement include being female, older, or having poor health. By contrast, having adult daughters who are not working diminishes the probability of retirement. The results show some unexpected statistical relationships. For example, net wealth and the expected present value of public pensions ${ }^{12}$ are negatively related to the probability of retirement, while the amount of hourly wage is positively associated with it.

The result for our net household wealth variable, which had a small negative coefficient (and not positive as expected), needs some qualifications. We suspect this might be caused by bias resulting from individual heterogeneity. For example, a worker who has stronger tastes for work (not fully captured by our explanatory variables) is likely to have accumulated a

\footnotetext{
${ }^{9}$ There is no a priori theory to determine the exact functional forms of the model. We tried various alternative specifications in the regression analyses, the results of which are not reported here. For educational attainment we used dummy variables on (1) no schooling, (2) elementary school, (3) middle school, (4) high school, and (5) college. We also included continuous variables in various forms such as polynomials and logarithms. Unless otherwise noted, the main implications of the results based on various specifications were generally similar to the results of our baseline regressions.

${ }^{10} 7.69$ percentage points estimated from the magnitude of the marginal effect (-0.0769) of SELFEMP divided by the probability of retirement for WS workers $(11.41 \%)$.

${ }^{11}$ If personal characteristics are not controlled, the raw difference in the probability between the self-employed and wage-and-salary workers is 5.4 percentage points; if sex and age are controlled, it is 8.6 percentage points.

${ }^{12}$ One possible reason for the limited effect of pensions is the relative immaturity of such programs in Korea. The National Pension Scheme (NPS), enacted with the National Pension Act in 1988, extended compulsory coverage over time and only became a universal scheme for the public in 2006. It first covered workplaces with ten or more employees in 1988, then workplaces with five or more employees in 1992, then rural workplaces with fewer than five employees as well as farmers and fishermen in 1995, and then the urban self-employed and urban workplaces with fewer than five workers in 1999. The NPS requires more than 20 years of contribution, and therefore few elderly are current beneficiaries. As of 2010, 19.1 million persons were enrolled in the NPS and 2.3 million received old-age pension benefits (NPS, 2010).
} 
greater amount of wealth and to work until a later age than a person with weaker preferences for work. An instrumental-variable approach correcting for this bias finds a positive (and more significant) effect of wealth on the probability of retirement. ${ }^{13}$

We also considered the effects of several job characteristics on the probability of retirement. 14 We constructed an industry-occupation fixed effect model with dummy variables on twodigit occupational and industrial categories. Finally, we used several subsamples to check robustness. Table 5 summarizes these additional regressions. It suggests that job characteristics, satisfaction, occupation (results not shown), and industry have little effect on the probability of retirement for self-employed and wage workers. Nevertheless, the magnitudes of the disparities considerably differ by age. For those aged at 55 to 59 , the probability of retirement does not differ between self-employed and wage workers, but the probability of retirement is lower for self-employed than wage workers for both younger and older than this age group. Particularly, for those aged 65 and older, wage workers are five times more likely to retire than self-employed.

Given the above results regarding personal characteristics, retirement incomes, and job characteristics, it appears the first four of our eight hypotheses, on wealth, health, job satisfaction, and mandatory retirement policy do not fully explain differences between the self-employed and wage-and-salary workers in probability of retirement. Below, we analyze further data on our hypotheses regarding the match of jobs and workers as well as job flexibility.

\section{Quality of Matching between the Job and the Worker}

How might the quality of job matching, denoted as $\left(\bar{Z}-Z_{i}\right)$ in Equation (1), explain the difference in retirement behaviors between the self-employed and wage-and-salary workers? A major obstacle to examining the quality of job matching is the difficulty in constructing a direct measure of it from available data. Some variables on job characteristics, especially measures of job satisfaction, could be related to the quality of matching between the worker and the job as well as the average quality of the job. This may be especially true if respondents evaluate their jobs based on their own subjective feelings. If respondents were to objectively compare their own jobs with others in determining their job satisfaction, then their answers should reflect an average quality of the job rather than the quality of matching.

With no direct measure of the quality of job matching, we offer several pieces of circumstantial evidence to suggest that the self-employed are better matched with their jobs because they have more heterogeneous jobs and are more able to adjust work efforts as they age.

We first compare the dispersions of work efforts and rewards for the self-employed and for wage-and-salary workers. Suppose that the self-employed, because of their more

\footnotetext{
${ }^{13} \mathrm{We}$ use variables regarding the place of residence and residence in an apartment as instruments. A large fraction of individual wealth is housing wealth which varies greatly by place of residence. Korean apartments are more expensive than other types of houses with comparable characteristics. Place of residence and type of housing are not likely to be strongly correlated with unobservable individual characteristics influencing labor-force participation at older ages. These instrumental variables should therefore help assess the effects of wealth on retirement decisions independent of other worker characteristics.

${ }^{14}$ Job-characteristic questions we examined include: (1) My job requires lots of physical effort, (2) My job requires lifting heavy loads, (3) My job requires stooping, kneeling, or crouching, (4) My job requires good eyesight, (5) My job requires intense concentration or attention, (6) My job requires skill in dealing with other people, (7) My job requires me to work with a computer, (8) My job requires me to do more difficult things than I am used to, (9) I am satisfied with the income I receive from my current job, (10) My job is stable, (11) I am satisfied with the working environment of my job, (12) I am satisfied with the job I do at my current job, (13) My job is stressful, and (14) I am satisfied with my current job. We constructed dummy variables with the value of "1" if the response to the question was positive (either "always or almost all of time" or "most of the time") and " 0 " otherwise (either "some of times" or "None or almost none of the time").
} 
heterogeneous jobs, have a wider range of combinations of minimum required work efforts $(\bar{Z})$ and wages than wage-and-salary workers do. If so, then their work hours and wages will be more widely dispersed.

Table 6 provides the standard deviations of weekly hours of work, monthly earnings, and hourly wages in 2006 and 2008 for the self-employed and for wage-and-salary workers. It indeed suggests that the hours and earnings for the self-employed are much more widely dispersed than those for wage-and-salary workers. (The result remains the same for other measures of dispersion, such as the coefficient of variation.) These results also show the self-employed, in comparison to wage-and-salary workers, are more likely to work extremely long or short hours or to have very low or very high earnings. This suggests that the self-employed are better able to find a job requiring the amount of effort they choose to offer.

Table 6 also shows standard deviations in changes in hours and wages for self-employed and wage-and-salary workers between 2006 and 2008. Again, the results show wider dispersion for the self-employed than for wage-and-salary workers. This indicates the self-employed were more likely to increase or decrease a given fraction of work effort between 2006 and 2008. Of course, these measures might also indicate the unstable nature of self-employment. Nevertheless, we consider it likely that self-employment offers more flexibility in choosing a combination of work effort and compensation.

We also tested how well the self-employed can match the requirements of their jobs with their physical capacity and tastes for work. If they are better able to do this than wage-andsalary workers are, then job characteristics related to work requirements should be a weaker influence on their retirement decisions. Hurd and McGarry (1993) offer a similar rationale in interpreting the link between health and retirement. Finding no relationship between physical difficulty of the job and the probability of continuing to work, they suggest individuals may indeed match with jobs that accord with their abilities. ${ }^{15}$

To test whether the self-employed can better match the requirements of their jobs with their physical capacity and tastes for work, we conducted logistic regression analyses separately for the self-employed and wage-and-salary workers. These are similar to those reported in Table 4 (but exclude the self-employment dummy variable). The results suggest that retirement decisions of the self-employed are not strongly related to weekly hours of work. For the self-employed, weekly hours of work appear to have no effect on the probability of retirement. Coefficients for all dummy variables on weekly hours of work are insignificant. For wage-and-salary workers, weekly hours of work affects retirement decisions. Those working either relatively short (40 to 49 hours) or very long hours ( 80 hours or more) are more likely to retire than those working 50 to 59 hours. These results are consistent with the hypothesis that the quality of matching between the job and the worker is better for the selfemployed than for wage-and-salary workers. Another notable result is that for, the selfemployed, the presence of adult daughters, especially those not working, strongly diminishes the probability of retirement.

The difference in job flexibility between the self-employed and wage-and-salary workers may be attributable to the greater ability of the self-employed to (1) adjust their work efforts in the same job (H6), and (2) switch to a less demanding job (H7). We attempt to determine the relative importance of each of these in the job flexibility of the self-employed. More specifically, we examine whether the greater ability of self-employed workers to change the

${ }^{15}$ Cited from McGarry (2004) 
number of hours they work is attributable to their ability to do so within the same job or to do so in different jobs.

We use the probability of reducing work hours by one-fifth or more between 2006 and 2008 as a measure of one's ability to change work effort with ageing. We include in this analysis individuals who were self-employed or wage-and-salary workers in both 2006 and 2008, were at least 45 years old in 2006, and worked at least 30 hours weekly in 2006.

The probability that workers of a particular type reduced their hours of work by 20 percent or more between 2006 and 2008, denoted as $P_{j}$, can be presented as the weighted average of the probabilities of workers who had remained in the same work place $\left(P_{j}^{N}\right)$ and of those who had switched to another workplace ( $P_{j}^{M}$ ), with $\varphi$ used as the weight to be applied to the first probability.

$$
P_{j}=\varphi P_{j}^{N}+(1-\varphi) P_{j}^{M}
$$

The difference between the self-employed and wage-and-salary workers in the probability of diminishing the hours by 20 percent or more (denoted as $\Delta P=P_{S}-P_{W}$ ) can be decomposed as:

$$
\Delta P=\left(P^{N}-P^{M}\right) \Delta \varphi+\varphi \Delta P^{N}+(1-\varphi) \Delta P^{M}
$$

In Equation (3), $S$ denotes the self-employed (SE), $W$ denotes wage-and-salary (WS) workers, $\Delta \varphi=\varphi_{S}-\varphi_{W}$, and $\Delta P^{N}=P_{s}^{N}-P_{W}^{N}$. The first term in the right-hand side of (3) represents the effect of the differences between the self-employed and wage-and-salary workers in the probability of switching jobs. The second term shows the effects of differences between the self-employed and wage-and-salary workers in the probability of reducing work hours within the same workplace, and the third term shows that by moving to a new workplace. If the different flexibility in changing jobs played an important role (as suggested by H7), then the magnitude of the first term on the probability of switching jobs should be relatively large. If the ability of adjusting work efforts within a job was a major cause (as H6 suggests), then the second and third terms on the probability of reducing hours or moving to a new work place should be relatively large.

Table 7 presents the estimates of the parameters given in Equation (3) and the result of decomposition for three age groups: ages 45 and older (Col. 1), ages 45-54 (Col. 2), and 55 and older (Col. 3). These results suggest that the self-employed are more likely than wageand-salary workers to reduce their hours of work by 20 percent or more. The difference between the self-employed and wage-and-salary workers in the likelihood of diminishing work effort was larger for workers aged 55 and older (about 12 percentage points) than for those aged 45 to 54 (3.8 percentage points). More significantly, the results suggest that the difference between the self-employed and wage-and-salary workers in the probability of reducing hours is explained entirely by the disparity between them in flexibility to adjust work efforts within a job. In particular, the difference in the probability of changing hours worked among those not changing workplaces appears to be the most important explanation of why the self-employed 45 and older were more likely than wage-and-salary workers to decrease their hours.

This result is consistent with the finding of Gustman and Steinmeier (1984). They found that partial retirement is quite common among U.S. wage-and-salary workers, but that this 
occurred outside their main job because most wage-and-salary workers are not free to retire partially in the job they hold at prime age. It is thus not surprising that the difference between the self-employed and wage-and-salary workers in the probability of reducing hours is largely attributable to differences in the flexibility workers have within their jobs.

Another study by Gustman and Steinmeier (1985) found that partial retirement negatively affects the wage rate. In particular, they found that the decrease in the wage rate associated with shorter hours of work is greater for partial retirement in a different job than in a job previously held. This suggests that, for modifying work efforts at an old age, selfemployment offers more attractive options than wage-and-salary jobs do. These options include both greater possibility of such an adjustment and reduced costs associated with it.

\section{Job Flexibility and Retirement}

Some of the evidence above suggests that self-employed workers are perhaps better able to match their work capacity and preference with job requirements. This may be a result of greater heterogeneity in jobs for the self-employed or the greater flexibility they have in choosing work efforts while remaining in the same job. We next consider whether higher quality of matching between job and work indeed diminishes the probability of retirement. We also consider whether differences in this matching by employment status can explain the differences between the self-employed and wage-and-salary workers in the probability of retirement.

An ideal approach to this question would be to relate a firm-level measure of the quality of matching to the retirement behaviors of workers employed in the firm. It would also be instructive to see how the probability of retirement differs for self-employed and wage-andsalary workers while controlling for such a firm-level measure of quality of matching. Unfortunately, we cannot calculate for each firm or workplace the likelihood of changing hours, which is our primary indirect measure of the quality of job matching. We therefore constructed an industry-level measure of the quality of matching indicating the proportion of workers whose hours of work diminished by more than 20 percent in each industry (IND_HOURS20). We added this variable to our logistic regressions (as reported in Table 4) on retirement decisions and presented the findings in Table 8. A clear drawback of this variable is that it cannot capture within-industry differences between self-employment and wage-and-salary jobs. Despite this serious limitation, the regression results reported in Table 9 are quite suggestive.

For the full sample, the reduction of hours by more than 20 percent has a strong negative effect on the probability of retirement. This indicates that workers in an industry with a greater flexibility of changing hours are less likely to retire than those employed in an industry with less flexibility. This supports the hypothesis that the quality of matching between the job and the worker is an important determinant of retirement decision.

Adding the measure of flexibility of hours does not reduce much the magnitude of the difference between self-employed and wage-and-salary workers in the probability of retirement. The absolute size of the marginal effect of the self-employment dummy diminishes only 8.3 percent (from -0.0767 reported in Column 1 in Table 4 to -0.0705 reported in Table 9). This might indicate that within-industry differences between selfemployment and wage-and-salary jobs in the quality of matching is more important than the industrial composition of these jobs.

Table 10 summarizes how the relationship between the measure of job flexibility and the probability of retirement varies by individual characteristics. It presents results of regression analyses for 20 different subsamples defined by employment status (SE and WS), gender, 
age (50-54, 55-59, 60-64, and 65 and older), and self-reported health ("Good," Fair," and "Poor").

For the full sample (Column 1), a male worker's retirement decision is much more responsive to variations in job flexibility than that of a female worker, for whom the effect of job flexibility (IND_HOURS20) on the probability of retirement is very small and statistically insignificant. ${ }^{16}$ There is apparently no influence of job flexibility on retirement decisions for workers less than 55 years of age, but the influence seems to be particularly strong for those 55 to 59 years old. For individuals aged 60 and older, the influence falls short of statistical significance and is smaller than that for workers 55 to 59 .

The results of regressions for subsamples defined by self-reported health suggest that the effect of job flexibility on retirement is strongest for workers with "fair" health. The statistical effect of our job-flexibility variable (IND_HOURS20) on retirement for those with "good" health is also strong, but its effect on workers with "poor" health is statistically insignificant.

The results for self-employed workers (Column 2) and wage-and-salary earners (Column 3) are roughly similar but with a few differences. The measure of job flexibility has a significant effect on male wage-and-salary workers and those with "fair" health. It does not have a significant effect for self-employed workers in these categories. One might conjecture that greater job flexibility may be more helpful for extending the career of an older worker with poor health than for a younger and healthier person. Nevertheless, our results suggest it matters more for retirement decisions of persons in the middle of age and health distributions. This may be because, for individuals who are quite old or severely limited by poor health, other determinants of retirement dominate those of job flexibility. For example, diminishing work efforts by 20 percent would not likely compensate for severe declines in productivity, deteriorating health, or other reductions in the quality of matching caused by ageing.

\section{Conclusions and Implications}

We have explored reasons for differences in the probability of retirement for the selfemployed and wage-and-salary earners. Our results confirm that the self-employed remain in the labour market longer than wage-and-salary workers.

We suggested eight possible hypotheses to explain these differences: H1) the self-employed are poorer and therefore have to work longer to accumulate enough money for retirement; H2) the self-employed are healthier and more productive and therefore can work to an older age; H3) the self-employed are more likely to have job characteristics more favorable for working in later life; $\mathrm{H} 4$ ) the self-employed can work longer because they do not have a mandatory or conventionally-determined retirement age; H5) because the self-employed have more heterogeneity in working conditions and the required minimum amount of work effort in their jobs, it is easier for them to find a job matched to them; H6) due to a greater job flexibility, the self-employed can better adjust their work efforts with changes in their tastes and productivity; H7) Within a given occupation or industry, the self-employed can more easily switch to a less demanding job; and H8) Individuals who retire later selectively enter self-employment.

\footnotetext{
${ }^{16}$ We do not have a strong explanation for this resfult, but some conjectures are: (1) female workers in the sample (mean age 57.6) are younger than male workers (mean age 59.3) and flexibility matters more for older workers; (2) only selected female workers with strong preferences for work remain in the labor market after age 50 their retirement decisions are less influenced by the flexibility of hours.
} 
Our results provide little evidence supporting the first four hypotheses. Controlling for differences in personal and job characteristics such as health, education, wealth, earnings, measures of job satisfaction, industry, and occupation little affects differences between the self-employed and wage-and-salary workers in the probability of retirement. Compulsory retirement for wage-and-salary workers does not explain the difference in the probability of retirement between wage-and-salary and self-employed workers.

We have suggested some indirect evidence on the importance of the matching between the minimum work efforts required by jobs and the desirable amount of work effort workers would choose to provide. Our results suggest that the distributions of work efforts and wages are more widely dispersed for the self-employed than for wage-and-salary workers. This is consistent with the hypothesis that, because self-employment provides a wider range of required minimum work efforts, the self-employed are more likely to be employed in a job well matched to their preferences or capacities. We have also found that the self-employed are more able to adjust their work efforts over time. Hours of work have a weaker influence on retirement of the self-employed. These results suggest that the self-employed are better able to match the requirements of their jobs with their physical capacity and tastes for work.

We found that the difference between the self-employed and wage-and-salary workers in the probability of reducing hours of work is explained entirely by the differences in job flexibility or the ability to adjust the hours of work within a job (supporting H6). The difference between the two categories of workers in the effects of switching jobs (H7) was trivial.

Finally, our results suggest that workers employed in an industry with more flexibility to change the number of hours they work are less likely to retire. This supports the hypothesis that the quality of matching between job and worker is an important determinant of retirement.

A major limitation of our analyses is that we do not have direct measures of the quality of matching and of the differences in unobservable characteristics related to self-selection in occupational choice. As a consequence, we cannot provide direct evidence on how the quality of matching affects retirement decisions. Nor can we determine the relative importance of the roles played by the quality of matching (H5, H6, and H7) and by the effect of self-selection (H8) in explaining the difference in the probability of retirement by employment status. These drawbacks call for further research.

There are several implications of our results. First, the type of employment is an important determinant of the timing of retirement when controlling for differences in personal and job characteristics. This implies that shifts in the employment structure, such as changes in the fraction of self-employees, should be a major cause of long-term change in the economic activity of older individuals. In particular, the high proportion of self-employed persons in Korea is likely to account for the relatively high labour-force participation rate of older people in Korea.

Second, if greater job flexibility rather than poverty is what influences the self-employed to remain in the labour market longer than wage-and-salary workers do, then self-employment could help boost employment of the elderly. Recent studies on the nature of selection into self-employment and the quality (i.e., educational attainment and occupational composition) of the self-employed in Korea offer somewhat mixed results on this possibility. Selfemployed Koreans are highly heterogeneous, and include both highly-talented individuals who voluntarily enter self-employment with expectations of high returns and marginal workers with low-ability who are pushed out of formal wage-and-salary jobs (Keum and 
Cho, 2000).The questions remain which type is relatively more important, and how does the composition of the self-employed change over time.

A number of recent studies suggest that an increasing proportion of the self-employed select their job voluntarily, and that their quality relative to that of wage-and-salary workers is improving over time. Ryoo (2000) show that the labour flows to and from the selfemployment sector, which is an indicator of the fragile labour-market status for the selfemployed, are largely confined to a relatively small group of marginal workers. They also found that the expected duration of self-employment has increased since 1990, suggesting that the employment stability of the self-employed has improved over time. Ryoo (2005) suggests self-employment has become more attractive in recent years and that the proportion of self-employed workers pushed out of wage-and-salary jobs has decreased, while the relative quality of the self-employed has improved, over time. ${ }^{17}$ Desired flexibility on the job does appear to be a significant reason for self-employment: the KLoSA indicates that three of four self-employed workers choose their job voluntarily, with 41 percent of the selfemployed saying they chose their job for its flexibility. ${ }^{18}$

Lastly, the reasons for the differences between the self-employed and wage-and-salary workers in retirement behaviors have implications for efforts to encourage the employment of the elderly. Our results suggest that eliminating mandatory retirement and practices of age discrimination may not be enough to increase the employment of older workers in wageand-salary jobs. Instead, enhancing job flexibility so that employees can adjust their work efforts by accepting lower wages as their preferences, health, and productivity change, could better encourage labour-force participation among the elderly.

Although this paper does not provide conclusive evidence, the presence of heterogeneous jobs that offer a wide range of required work efforts, wages, and flexibility of work schedule may also help boost labour-force participation among older persons. As for related labourmarket policies, to encourage the employment of older persons it would be desirable to loosen such labour-market regulations as those that standardize wages, hours, and other work conditions across various jobs and within a particular job. It would also be helpful to drop the regulations that make it difficult for employers and employees to adjust work efforts and wages.

\section{References}

Aubert, Patric; Caroli, Eve; Roger, Muriel. New Technologies, Organization, and Age: Firm-Level Evidence. Economic Journal. 2006; 116:F73-F93.

Bartel A, Sicherman N. Technological Change and Retirement Decisions of Older Workers. Journal of Labor Economics. 1993; 11(1):162-183.

Boskin MJ. Social Security and Retirement Decisions. Economic Inquiry. 1977; 15:1-25.

Chang, J. Transition Paths from Work to Retirement. Paper presented at the OECD/KLI International Conference on Labor Market Policies in an Aging Era; Seoul. 2002.

Cheon, Byung-You. A Study of Selection of Self-Employment in Korea. Korean Journal of Labor Economics. 2003; 26(3):149-179.

\footnotetext{
${ }^{17}$ There is additional evidence suggesting that the quality of self-employed workers has improved over time. Since 1982, the educational attainment of the self-employed has increased more rapidly than that of wage-and-salary workers. Though most selfemployed are employed in service and sales, the occupational composition of the self-employed has greatly improved. For example, the percentage of self-employed who are either professionals or semi-professionals increased from 4.1 percent in 1982 to 16.3 percent in 2004 (Keum and Yoon, 2005).

18 The percentage distribution of each reply to the reason for self-employment is as follows: (1) Because I can earn more money (28.9 percent); (2) Because it is the work I wanted to do (4.9 percent); (3) Because it gives me more flexibility (41.3 percent); (4) Because of tax benefits ( 0.1 percent); (5) Because I could not get a wage job I wanted (10.1 percent); (6) Because it was difficult to get a wage job (13.1 percent); and (7) Other reasons (1.6 percent).
} 
Cho, Joonmo; Kim, Sunwoong. On Using Mandatory Retirement to Reduce Workforce in Korea. International Economic Journal. 2005; 19:283-303.

Choi, Seung-Hyun. Retirement Behaviors of Two Wage Earners Households. Korean Journal of Labor Economics. 2006; 29(1):129-152.

Coile, Courtney; Levine, Phillip. Bulls, Bears, and Retirement Behavior. Industrial and Labor Relations Review. 2006; 59(3):408-429.

Costa, Dora L. The Evolution of Retirement. Chicago: University of Chicago Press; 1998.

Leora, Friedberg. The Impact of Technological Change on Older Workers: Evidence from Data on Computer Use. Industrial and Labor Relations Review. 2003; 56(3):511-529.

Friedberg, Leora; Webb, Anthony. Retirement and the Evolution of Pension Structure. Journal of Human Resources. 2005; 40:281-308.

Gruber J, Madrian BC. Health Insurance Availability and the Retirement Decision. American Economic Review. 1995; 87:192-205.

Gruber, J.; Wise, D. Social Security and Retirement around the World. Chicago: University of Chicago Press; 1999.

Gruber, J.; Wise, D. Social Security Programs and Retirement around the World: Micro-Estimation. Chicago: University of Chicago Press; 2004.

Gustman, Alan L.; Steinmeier, Thomas L. Partial Retirement and the Analysis of Retirement Behavior. Industrial and Labor Relations Review. 1984; 37:403-415.

Gustman, Alan L.; Steinmeier, Thomas L. The Effect of Partial Retirement on the Wage Profiles of Older Workers. Industrial Relations. 1985; 24:257-265.

Hurd, Michael D. The Effect of Labor Market Rigidities on the Labor Force Behaviors of Older Workers. In: Wise, Daivd W., editor. Advances in the Economics of Aging. Chicago: University of Chicago Press; 1996. p. 11-60.

Hurd, Michael D.; Boskin, MJ. The Effect of Social Security on Retirement in the Early 1970s. Quarterly Journal of Economics. 1984; 99:767-790.

Hurd, MD.; McGarry, K. NBER Working Paper. National Bureau of Economic Research; 1993. The Relationship between Job Characteristics and Retirement; p. 4558

Keum J, Cho J. Theory and Empirical Analysis of Selection into Self-Employed Jobs. Korean Journal of Labor Economics. 2000; 23(S):81-107.

Keum J, Yoon M. Change and Trend of the Employment Structure of Self-Employment. Labor Review. 2005 May.5:15-30.

Kim, Hak-Ju; Yoo, Kyung-Sook. Determinants of Reemployment of the Elderly Workers. Journal of the Korea Gerontological Society. 2004; 24(2):97-110.

Krueger AB, Pischke J. The Effect of Social Security on Labor Supply: A Cohort Analysis of the Notch Generation. Journal of Labor Economics. 1992; 10:412-437.

Lee, Chulhee. Rise of the Welfare State and Labor Force Participation of Older Males. American Economic Review. 1998; 88:222-226.

Lee, Chulhee. The Expected Length of Male Retirement in the United States, 1850-1990. Journal of Population Economics. 2001; 14:641-650.

Lee, Chulhee. Sectoral Shift and Labor-Force Participation of Older Males in America, 1880-1940. Journal of Economic History. 2002; 62:512-523.

Lee, Chulhee. Long-Term Changes in the Economic Activity of Older Males in Korea. Economic Development and Cultural Change. 2007; 56(1):99-124.

Lee, Chulhee. Retirement Expectations of Older Self-Employed Workers in Korea: Comparisons with Wage and Salary Workers. Korean Economic Review. 2008; 24(1):33-71.

McGarry, Kathleen. Health and Retirement: Do Changes in Health Affect Retirement Expectation? Journal of Human Resources. 2004; 39:624-648.

NPS, National Pension Service. 2010. Retrieved on December 12, 2010, from http://www.nps.or.kr/ jsppage/etc/data/data01_01.jsp

Park, Keong-Suk. The Effect of Work Status during Middle Life on the Retirement Process Later in Life Course. Korean Journal of Labor Economics. 2001; 24(1):177-205. 
Park, Keong-Suk. Labor Exit Process of Old Workers Aged 55 and Over: Implications for Typology of Retirement. Labor Policy Studies. 2003; 3(1):103-140.

Parsons DO. The Decline in Male Labor Force Participation. Journal of Political Economy. 1980; 88:117-134.

Parsons DO. Male Retirement Behavior in the United States, 1930-1950. Journal of Economic History. 1991; 51:657-674.

Pedersen H. A Cultural Evaluation of the Family Farm Concept. Land Economics. 1950; 26:52-64.

Quinn, Joseph; Burkhauser, Richard; Meyers, Daniel. Passing the Torch: The Influence of Economic Incentives on Work and Retirement. Kalamazoo, MI: Upjohn Institute; 1990.

Ryoo, Jaewoo. Earnings Opportunity in Self-Employment Sector and Workers' Self-Selection. Economic Studies. 2005; 52:5-32.

Ryoo, Jaewoo. Labor Market Dynamics in the Self-Employed Sector in Korea. Korean Journal of Labor Economics. 2000; 22(1):137-165.

Sung, Jaimie; Ahn, Jo-yup. Self-Employment as Bridge Employment. Korean Journal of Labor Economics. 2004; 27(2):1-27.

Sung, Jaimie; Ahn, Jo-yup. What Makes the Older Work for Satisfactory Lives? Labor Policy Studies. 2006; 6(1):39-74. 


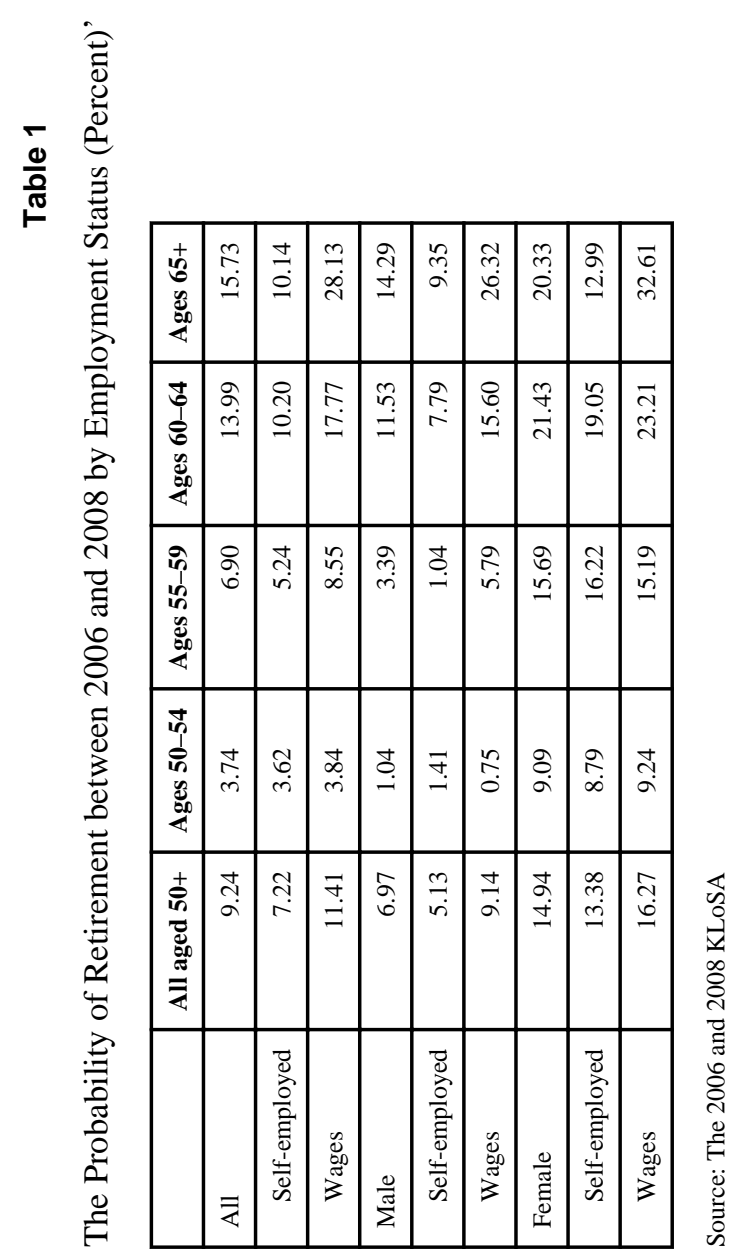

J Popul Ageing. Author manuscript; available in PMC 2014 June 01. 
Table 3

Definition of Variables Used in the Regression Analysis

\begin{tabular}{|c|l|}
\hline Variable & Definition \\
\hline SELFEMP & $=1$ if the person is self-employed, $=0$ otherwise \\
\hline MALE & $=1$ if the person is male, $=0$ otherwise \\
\hline AGE & 2006 Age \\
\hline SCHOOL & The years of schooling \\
\hline MARRIED & $=1$ if the person is married, $=0$ otherwise. \\
\hline SP_WORK & $=1$ if the person is married and his/her spouse work, $=0$ otherwise. \\
\hline MCHD_WORK & The number of male adult children ( 19 and older) who work \\
\hline MCHD_NOWORK & The number of male adult children $(19$ and older) who work \\
\hline FCHD_WORK & The number of female adult children (19 and older) who work \\
\hline FCHD_NOWORK & The number of female adult children (19 and older) who work \\
\hline HL_BAD & $=1$ if self-reported health is poor or very poor, $=0$ otherwise \\
\hline WEALTH & Net household wealth (100 million Won) \\
\hline PUBPEN & The expected present value of public pensions (100 million Won) \\
\hline PVTPEN & The expected present value of private pensions (10 million Won) \\
\hline NLINCOME & The total value of non-labor incomes ( 10 million Won) \\
\hline HWAGE & The hourly wages ( 10 thousand Won) \\
\hline HOURS30 & $=1$ if the weekly hours of work is 30 to 39 hours, $=0$ otherwise \\
\hline HOURS40 & $=1$ if the weekly hours of work is 40 to 49 hours, $=0$ otherwise \\
\hline HOURS50 & $=1$ if the weekly hours of work is 50 to 59 hours, $=0$ otherwise \\
\hline HOURS60 & $=1$ if the weekly hours of work is 60 to 69 hours, $=0$ otherwise \\
\hline HOURS70 & $=1$ if the weekly hours of work is 70 to 79 hours, $=0$ otherwise \\
\hline HOURS80 & $=1$ if the weekly hours of work is 80 hours or longer, $=0$ otherwise \\
\hline
\end{tabular}

Note: The expected present value of public pension is computed based on each respondent's expectations about the amount of National Pension benefits and the age at which he/she begins to receive pensions. The expected present value of private pensions is calculated by summing up the expected present values of all private annuity insurances (computed from the information on the expected amounts of benefits and ages at which the respondent begins to receive them) and the expected value of severance pays (computed based on the amount of monthly wage, the length of tenure, and the timing of early liquidation of severance pay, if any). A discount rate of $3 \%$ is applied to the computation. 


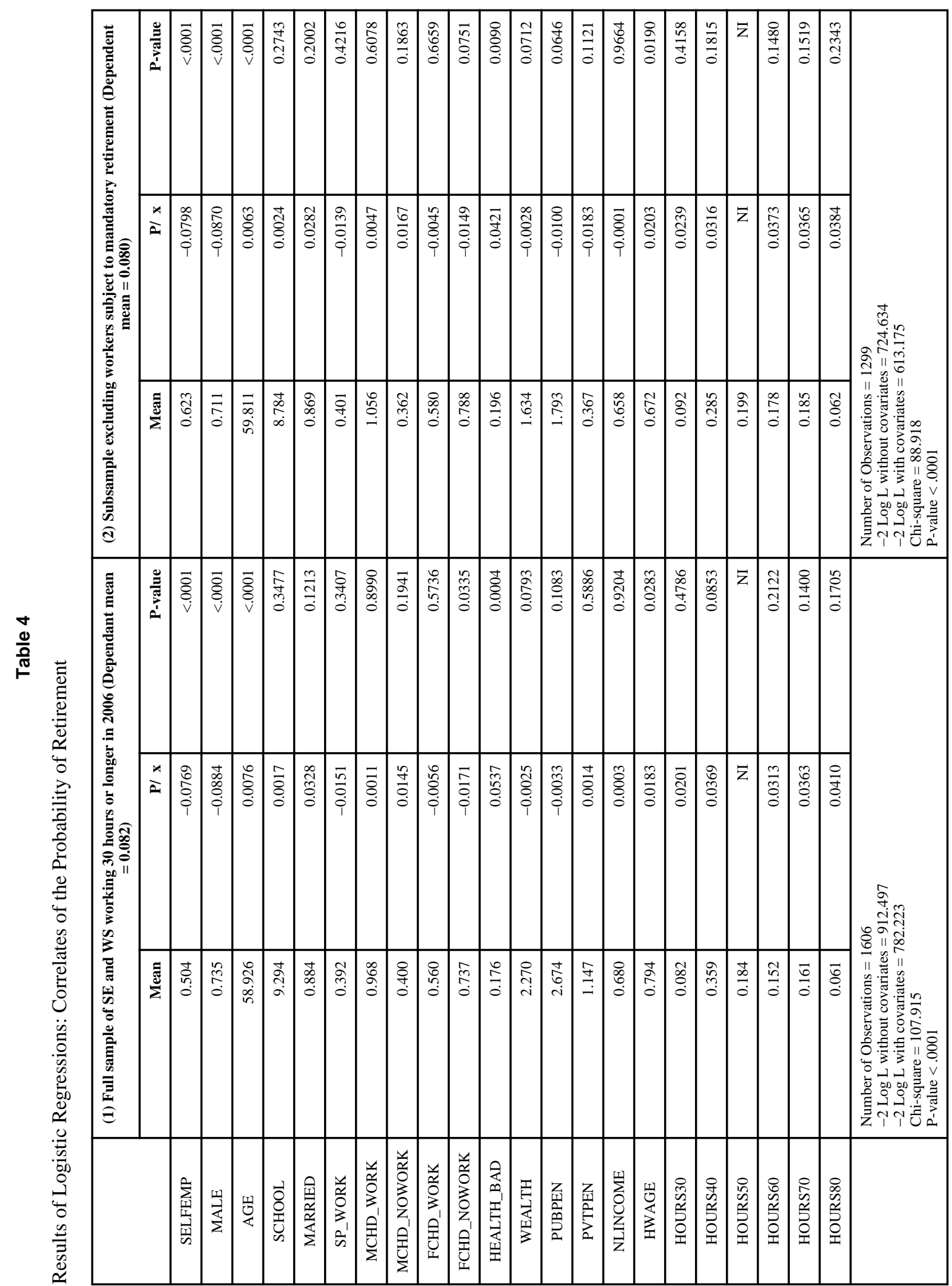




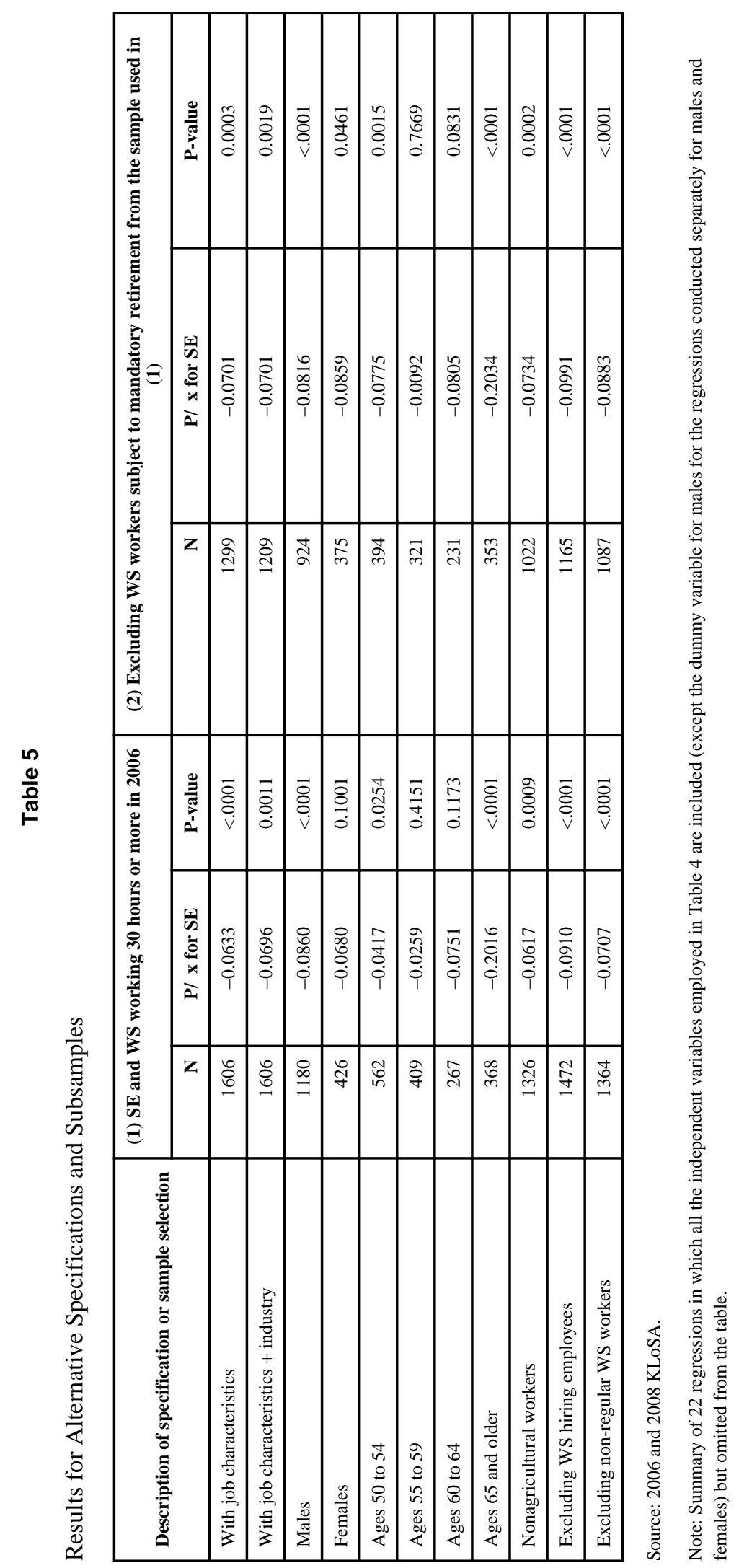


Table 6

Comparison of Some Measures of Job Flexibility between SE and WS

\begin{tabular}{|l|r|r|l|}
\hline & (1) Self-Employed & (2) Wage and Salary & (3) (1)/(2) \\
\hline SD of 2006 weekly hours & 14.918 & 12.616 & 1.182 \\
\hline SD of 2008 weekly hours & 17.001 & 12.113 & 1.404 \\
\hline SD of 2006 earnings & 373.856 & 123.967 & 3.016 \\
\hline SD of 2008 earnings & 211.175 & 139.065 & 1.519 \\
\hline SD of 2006 hourly wages & 2.009 & 0.769 & 2.612 \\
\hline SD of 2008 hourly wages & 1.232 & 0.865 & 1.424 \\
\hline SD of the rate of change in hours & 0.305 & 0.255 & 1.196 \\
\hline SD of the rate of change in earnings & 1.273 & 0.629 & 2.024 \\
\hline SD of the rate of change in wages & 2.037 & 0.751 & 2.712 \\
\hline$\%$ hours decreased by $10 \%$ between 06 and 08 & 43.466 & 34.652 & 1.254 \\
\hline$\%$ hours decreased by $20 \%$ between 06 and 08 & 29.194 & 20.550 & 1.421 \\
\hline$\%$ hours decreased by $30 \%$ between 06 and 08 & 17.701 & 11.350 & 1.560 \\
\hline$\%$ hours increased by 20\% between 06 and 08 & 23.132 & 18.057 & 1.281 \\
\hline$\%$ earnings decreased by 20\% between 06 and 08 & 37.257 & 13.672 & 2.725 \\
\hline$\%$ earnings increased by 20\% between 06 and 08 & 32.437 & 31.642 & 1.025 \\
\hline$\%$ wages decreased by 20\% between 06 and 08 & 35.589 & 16.939 & 2.101 \\
\hline$\%$ wages increased by $20 \%$ between 06 and 08 & 37.164 & 39.982 & 0.930 \\
\hline
\end{tabular}

Source: 2006 and 2008 KLoSA.

Note: The sample is limited to the self-employed and wage and salary workers working 30 hours or more in 2006 who remained in the same employment status by 2008 . 
Table 7

Decomposition of the Difference between Self-employees and Wage and Salary Workers in the Probability of Diminishing the Hours of Work by 20 Percent or More from 2006 to 2008.

\begin{tabular}{|c|c|c|c|}
\hline Variable & Ages 45 and older N= 2242 & Ages 45-54 N=1287 & Ages 55 and older N=955 \\
\hline$P_{S}$ & 0.292 & 0.232 & 0.345 \\
$P_{W}$ & 0.206 & 0.194 & 0.228 \\
$\varphi_{S}$ & 0.982 & 0.972 & 0.990 \\
$\varphi_{W}$ & 0.887 & 0.895 & 0.871 \\
$\varphi$ & 0.933 & 0.925 & 0.942 \\
$P_{S}^{N}$ & 0.290 & 0.230 & 0.342 \\
$P_{S}^{M}$ & 0.400 & 0.286 & 0.667 \\
$P_{W}^{N}$ & 0.200 & 0.189 & 0.223 \\
$P_{W}^{M}$ & 0.252 & 0.244 & 0.265 \\
$P^{N}$ & & 0.206 & 0.298 \\
$P^{M}$ & 0.245 & 0.250 & 0.309 \\
\hline$\Delta P$ & 0.272 & 0.038 & 0.117 \\
$P^{N}$ & 0.086 & -0.003 & -0.001 \\
$\left.P^{M}\right) \Delta \varphi$ & -0.003 & 0.038 & 0.112 \\
$(1-\varphi) \Delta P^{N}$ & 0.084 & 0.003 & 0.023 \\
\hline & 0.010 & & \\
\hline
\end{tabular}

Note. See text for the definition of each variable. The parameters are calculated from the 2006 and 2008 KLoSA. The sample is limited to workers who worked for 30 hours or longer in 2006. 


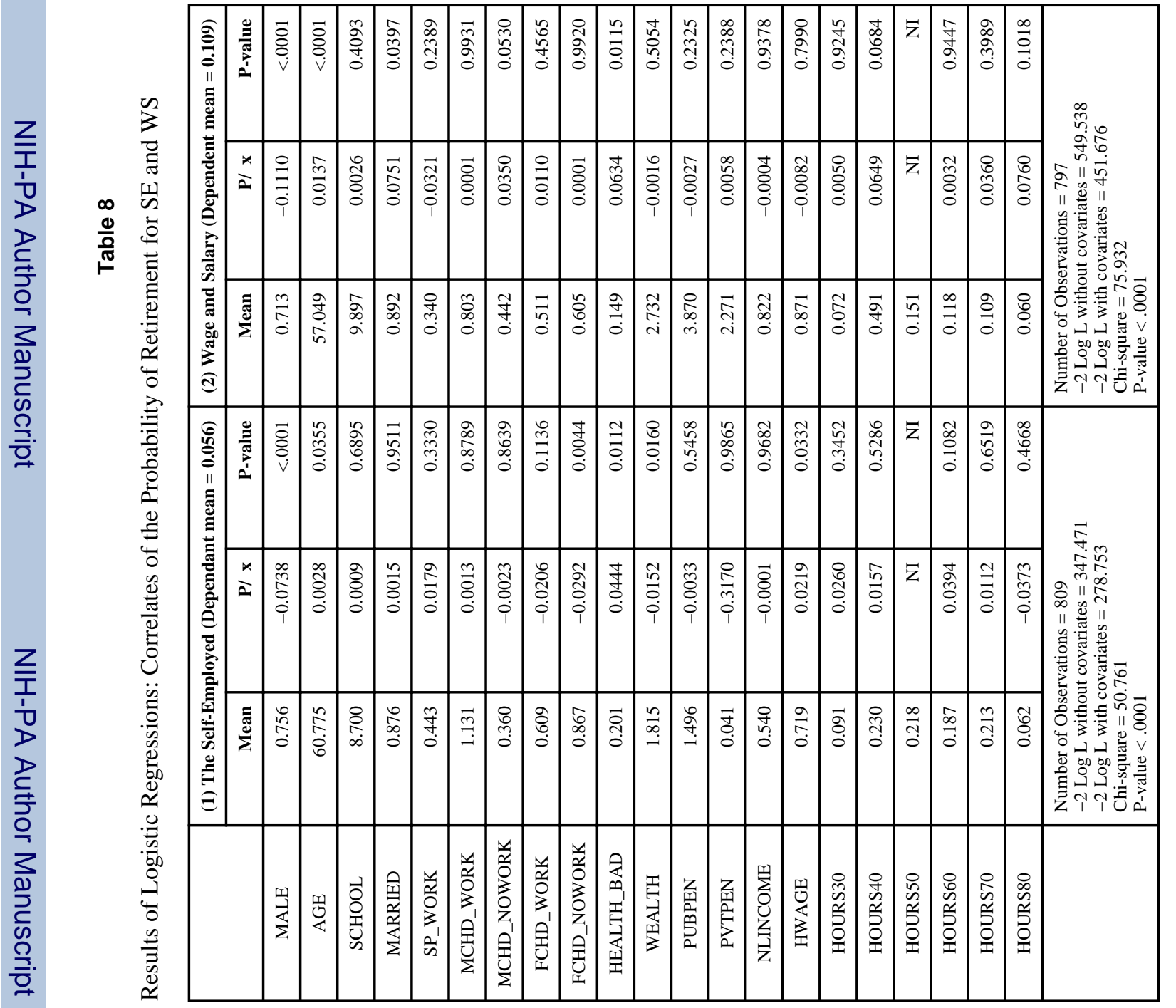

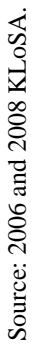


Table 9

Results of Logistic Regressions: Flexibility of Hours and the Probability of Retirement

\begin{tabular}{|c|c|c|c|}
\hline & \multicolumn{3}{|c|}{ SE and WS working 30 hours or more in $2006($ Dependant mean $=0.082)$} \\
\hline & Mean & $\partial \mathbf{P} / \partial \mathbf{x}$ & P-value \\
\hline SELFEMP & 0.510 & -0.0705 & $<.0001$ \\
\hline IND_HOURS20 & 25.416 & -0.0018 & 0.0433 \\
\hline MALE & 0.739 & -0.0827 & $<.0001$ \\
\hline AGE & 58.990 & 0.0074 & $<.0001$ \\
\hline SCHOOL & 9.277 & 0.0014 & 0.4680 \\
\hline MARRIED & 0.885 & 0.0346 & 0.1078 \\
\hline SP_WORK & 0.392 & -0.0135 & 0.4220 \\
\hline MCHD_WORK & 0.970 & 0.0035 & 0.6881 \\
\hline MCHD_NOWORK & 0.400 & 0.0154 & 0.1754 \\
\hline FCHD_WORK & 0.562 & -0.0036 & 0.7163 \\
\hline FCHD_NOWORK & 0.740 & -0.0150 & 0.0640 \\
\hline HEALTH_BAD & 0.175 & 0.0527 & 0.0005 \\
\hline WEALTH & 2.272 & -0.0027 & 0.0671 \\
\hline PUBPEN & 2.695 & -0.0035 & 0.0898 \\
\hline PVTPEN & 1.107 & 0.0004 & 0.8877 \\
\hline NLINCOME & 0.689 & 0.0001 & 0.9822 \\
\hline HWAGE & 0.790 & 0.0182 & 0.0279 \\
\hline HOURS30 & 0.079 & 0.0174 & 0.5484 \\
\hline HOURS40 & 0.356 & 0.0355 & 0.0961 \\
\hline HOURS50 & 0.186 & NI & $\mathrm{NI}$ \\
\hline HOURS60 & 0.154 & 0.0250 & 0.3212 \\
\hline HOURS70 & 0.163 & 0.0383 & 0.1175 \\
\hline \multirow[t]{2}{*}{ HOURS80 } & 0.062 & 0.0379 & 0.2038 \\
\hline & \multicolumn{3}{|c|}{$\begin{array}{l}\text { Number of Observations }=1579 \\
-2 \log \mathrm{L} \text { without covariates }=893.383 \\
-2 \log \mathrm{L} \text { with covariates }=759.616 \\
\text { Chi-square }=108.058 \\
\text { P-value }<.0001\end{array}$} \\
\hline
\end{tabular}

Source: 2006 and 2008 KLoSA.

Note: Workers for whom the information on industry is missing $(\mathrm{N}=23)$ and those who were employed in domestic service (N=6) are excluded from the sample because the variable IND_HOURS20 could not be computed for them. 


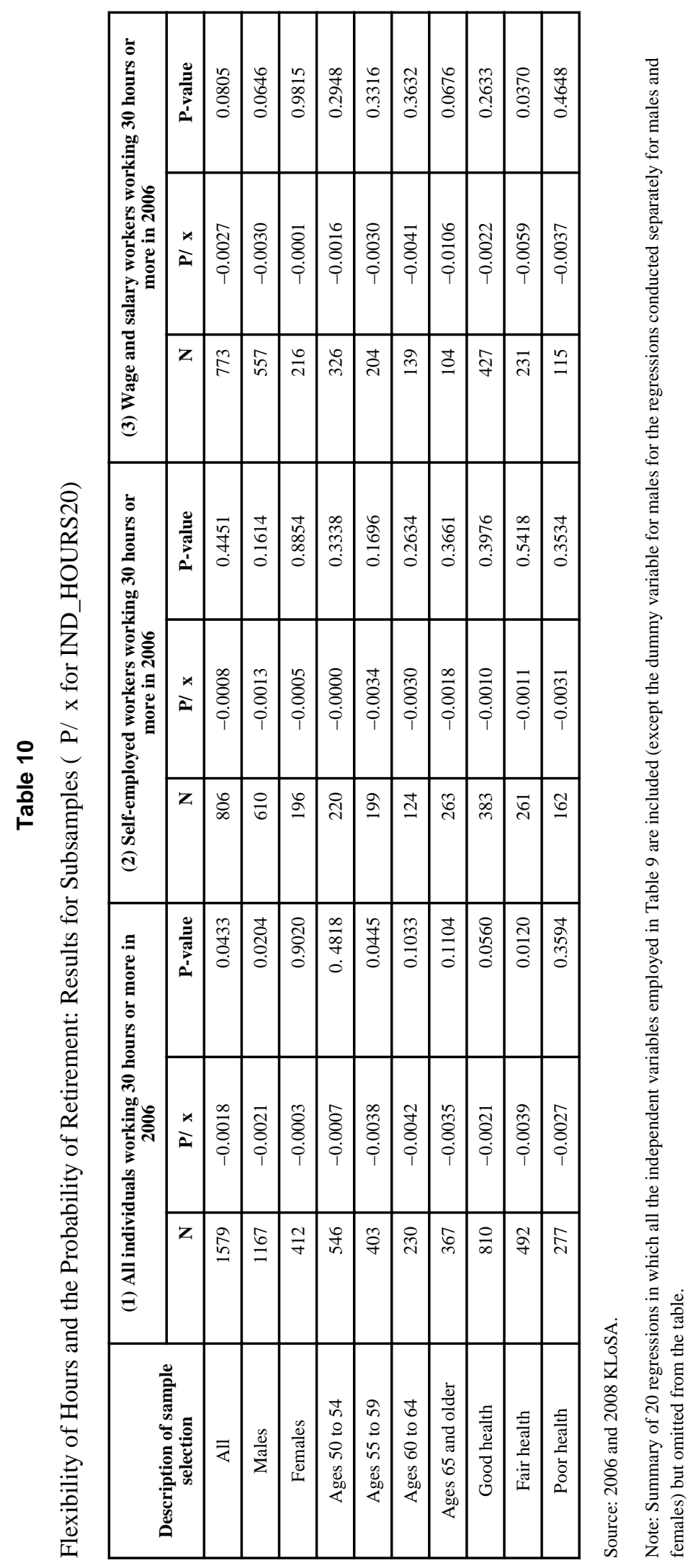

J Popul Ageing. Author manuscript; available in PMC 2014 June 01. 